\title{
PEMBERDAYAAN MASYARAKAT NELAYAN MELALUI PELATIHAN PENGAWETAN IKAN MENGGUNAKAN MESIN PENDINGIN
}

\author{
N. Suarnadwipa ${ }^{1}$, I.W.B. Adnyana ${ }^{2}$, H. Wijaksana ${ }^{3}$, dan N.M. Suaniti ${ }^{4}$
}

\begin{abstract}
ABSTRAK
Kemampuan kelompok nelayan tradisional di bidang kemampuan teknologi pengolahan ikan masih sangat rendah. Hal ini disebabkan kurangnya pengetahuan dan terbatasnya sarana-prasarana yang mendukung. Sehingga berdampak pada pendapatan nelayan menjadi tidak maksimal. Teknologi pengolahan ikan merupakan suatu metode untuk menjaga kondisi ikan agar bisa bertahan lama dan tidak mudah rusak. Dari beberapa teknologi yang ada, pada pelaksanaan pengabdian masyarakat ini bertujuan untuk meningkatkan pemberdayaan masyarakat nelayan tentang proses pengawetan ikan dengan menggunakan mesin pendingin. Mitra pengabdian yang dipilih adalah kelompok nelayan Amertha Segara yang berlokasi di Desa Bugbug, Kabupaten Karangasem. Metode pelaksanaan pengabdian masyarakat meliputi melakukan survey awal, melakukan evaluasi kemampuan masyarakat sebelum pelatihan, memberikan penyuluhan dan pelatihan pengawetan ikan menggunakan mesin pendingin, mengevaluasi pehaman masyarakat pasca pelatihan dan memberikan bimbingan teknis tentang pengoperasian dan perwatan mesin pendingin. Dari hasil yang diperoleh pada awalnya kemampuan masrakat nelayan tentang mekanisme pengawetan ikan menggunakan mesin pendingin masih sangat rendah, setelah adanya penyuluhan dan pelatihan pemahaman masyarakat menjadi meningkat, masyarakat mengikuti penyuluhan dan pelatihan sampai akhir dengan semangat.
\end{abstract}

Kata Kunci : pemberdayaan, nelayan, pengawetan, ikan, mesin pendingin

\begin{abstract}
The ability of traditional fishermen groups in the field of fish processing technology capability is still very low. This is due to the lack of knowledge and the limited supporting facilities. That it to impact on the income of fishermen to be not maximal. Fish processing technology is a method to maintain the condition of the fish in order to survive long and not easily damaged. From several the existing technologies, the implementation of community service aims to improve the empowerment of fishermen community about the process of preservation of fish by using a cooling machine. The chosen service partner is the fishermen community of Amertha Segara is located in the Bugbug Village, Karangasem District. Methods of community service implementation include conducting preliminary surveys, evaluating community skills before training, providing counseling and training of fish preservation using a cooling machine, evaluating the community's post-training activities and providing technical guidance on the operation and maintenance of the cooling machine. From the initial results, the capability of the fishermen to fish preservation mechanism using the cooling machine is still very low, after the counseling and training of community understanding becomes increasing, the society were followed the counseling and training to the end with enthusiasm.
\end{abstract}

Keywords : empowerment, fisherman, fish preservation, cooling machine

${ }^{1}$ Jurusan Teknik Mesin, Fakultas Teknik, Universitas Udayana, Bukit Jimbaran, Badung, 80361

Telp/Fax : 0361 703321,E-mail : n.suarnadwipa@unud.ac.id

2 Jurusan Teknik Mesin, Fakultas Teknik, Universitas Udayana, Bukit Jimbaran, Badung, 80361

${ }^{3}$ Jurusan Teknik Mesin, Fakultas Teknik, Universitas Udayana, Bukit Jimbaran, Badung, 80361

${ }^{4}$ Jurusan Kimia, Fakultas MIPA, Universitas Udayana, Bukit Jimbaran, Badung, 80361 


\section{PENDAhUluan}

Luas laut Indonesia mencakup 2/3 dari seluruh luas wilayah Indonesia, yaitu 5,8 juta $\mathrm{km}^{2}$ [DKP Bali, 2008]. Sedangkan Perairan Bali Timur dengan luas $\pm 1.730,89 \mathrm{~km}^{2}$ atau $\pm 0,03 \%$ dari luas laut Indonesia yang meliputi perairan pantai Kabupaten Karangasem, Klungkung dan Gianyar. Laut merupakan sumber daya alam yang merupakan anugrah Tuhan. Di dalam laut tersimpan kekayaan alam yang luar biasa besarnya. Potensi sumber daya laut Indonesia salah satunya adalah berupa ikan. Potensi lestari sumber daya ikan perairan Bali Timur diperkirakan sebesar 19.455,6 ton/tahun. Jenis potensi sumber terutama terdiri dari ikan tongkol, cakalang, cucut, tembang dan jenis-jenis ikan karang lainnya (DKP Bali, 2014).

Masyarakat yang tinggal di daerah pesisir sebagian besar menggantungkan hidupnya menjadi nelayan. Kelangsungan hidup nelayan sangat tergantung pada potensi laut sekitarnya, kemampuan teknologi menangkap ikan, kemampuan teknologi pengolahan ikan serta kemampuan manajemen pemasarannya. Kemampuan masyarakat di bidang pengelolaan hasil tangkapan ikan sangat penting untuk mendapatkan perhatian, hal ini sangat terkait dengan kestabilan persediaan ikan di pasaran. Pengolahan ikan yang bertujuan menyimpan ikan dalam waktu lama sehingga harga ikan dapat dipertahankan lalu berdampak pada peningkatan pendapatan masyarakat nelayan menuju berkehidupan yang lebih sejahtera.

Di desa-desa pesisir banyak dijumpai kelompok nelayan yang sudah memiliki legalitas dari pemerintah daerah setempat. Salah satu dari kelompok nelayan yang ada adalah kelompok nelayan "Amerta Segara" yang bertempat di Desa Bugbug-Karangasem Bali. Kelompok nelayan ini diketuai oleh I Wayan Sudarta yang beranggotakan \pm 28 orang. Tingkat pendidikan anggota adalah berpendidikan SD, SMP dan SMA. Peralatan yang digunakan melaut masih sangat. Kegiatan dari kelompok nelayan sebagian beasr adalah menangkap ikan, jual beli ikan, jual beli alat penangkap ikan. Tangkapan jenis ikan tongkol merupakan tangkapan musiman, yang sangat tergantung kondisi cuaca, kondisi arus laut. Keberadaan ikan hasil tangkapan tidak menentu, kadang sedikit bahkan kosong dan kadang berlimpah. Kemampuan kelompok nelayan ini di bidang kemampuan teknologi menangkap ikan masih kurang memadai, kemampuan di dalam pengolahan ikan pasca tangkap masih rendah serta kemampuan manajemen pemasaran masih sangat kurang. Hal ini disebabkan kurangnya sarana dan prasarana yang moderen yang dimiliki nelayan untuk menangkap ikan dan kurangnya pemahaman atau pengetahuan di bidang pengawetan ikan untuk menstabilkan persediaan hasil produksi melaut dan terbatasnya kemampuan dalam hal manajemen pemasaran. Sehingga berdampak pada hasil pendapatan kelompok nelayan tidak maksimal.

\section{METODE PELAKSANAAN}

Metode pelaksanaan pengadian kepada masyarakat, di awal mengajak masyarakat nelayan untuk berkumpul menyampaikan keluhan-keluhan atau kendala yang dialami kelompok nelayan selama ini. Mengajak masyarakat nelayan berkumpul untuk mendengarkan pelatihan pengawetan ikan menggunakan mesin pendingin ikan. Materi pelatihan meliputi teori yang meliputi teknik pengawetan ikan dengan mesin pendingin, pengenalan mesin pendingin beserta komponennya, prinsip kerja mesin pendingin, cara perawatan mesin pendingin. Melakukan diskusi tentang materi yang disampaikan. Tim pengabdian melakukan pelatihan praktek, teknik pengawetan ikan dengan mesin pendingin, pengenalan mesin pendingin beserta komponennya, praktek perawatan mesin pendingin. Melakukan diskusi tentang materi praktek yang didemontrasikan. Kemudian mengajak masyarakat nelayan untuk berkumpul untuk mempraktekkan langsung proses pengawetan ikan menggunakan mesin pendingin. Selalu mendampingi dan memberikan bimbingan didalam mewujudkan atau menerapkan teknologi pengawetan/pengolahan ikan menggunakanan mesin pendingin di kemudian hari. 


\section{HASIL DAN PEMBAHASAN}

Pada kegiatan pelaksanaan pengabdian kepada kelompok nelayan sebagai mitra dalam pengabdian masyarakat ini dimana yang menjadi objeknya adalah kelompok nelayan Amertha Segara di Desa Bugbug Karangasem-Bali. Kegiatan ini dilakukan bermula dari survei awal ke lokasi calon tempat pengabdian. Dengan melakukan analisis situasi dan merangkum permasalahan yang ada kemudian dibuatkan usulan ke LPPM Unud agar bisa didanai. Seiring dengan perjalanan waktu usulan kemudian didanai, selajutnya tim pengabdi merancang atau menyusun rencana kerja pengabdian. Sesuai dengan tema yang ditawarkan dalam pengabdian" Pemberdayaan Masyrakat Nelayan melalui Pelatihan Pengawetan Ikan menggunakan Mesin Pendingin", maka metode yang dilaksanakan adalah metode pelatihan. Tujuan pelatihan untuk dapat memperdayakan masyarakat nelayan secara umum agar lebih memahami dan mengetahui tentang teknologi pengolahan ikan secara umum dan memahami pengawetan ikan dengan mesin pendingin. Selain itu agar memahami bagaimana proses pembekuan ikan dan mengerti mengoperasikan mesin pendingin dan mengerti dalam perawatannya. Pelatihan dikosentrasikan pada materi teknologi pengolahan ikan secara umum dan materi teknologi pengawetan ikan menggunakan mesin pendingin/frezeer secara khusus.

Sebelum pelaksanaan pelatihan, tim pengabdi berkoordinasi membuat rencana kerja dan membuat modul pelatihan. Modul yang dibuat yang berisikan materi teknologi pengolahan ikan secara umum dan memuat materi teknologi pengawetan ikan menggunakan mesin pendingin /frezeer. Dalam penyusunan modul ada beberapa referensi yang digunakan terkait materi yang disampaikan meliputi studi kelayakan dan efisiensi usaha pengasapan ikan dengan asap cair limbah pertanian (Swastawati at al., 2011), oksidasi lemak ikan tongkol (Sanger at, al.,2010), industry pengolahan ikan (Wibowo, 1996), refrigeration and air conditioning and air conditioning (W.F. Stoecker, 1980), pengolahan ikan dan pengawetan ikan (Adawyah, 2007), teknik pengolahan ikan (Junianto2003), karakteristik fisik kimia dan organoleptik ikan cakalang (Isamu Kobajashi T., at al.,2012). Sebelum melakukan pelatihan tim berkoordinasi dengan ketua kelompok nelayan untuk menentukan jadwal pelaksanaan kegiatan dan tim pengabdi menyiapkan segala hal yang meliputi pembuatan sepanduk, menyiapkan modul dan memperbanyak, menyiapkan konsumsi makan siang, menyiapkan kue kotak, menyiapkan transpotasi dan yang lainnya.

Setelah semuanya siap, dalam pelaksanaan pelatihan yang dijadwalkan, tim pengabdi melakukan presentasi tentang materi. Sebelum presentasi dimulai diadakan test untuk mengetahui tingkat pemahaman sebelum dan sesudah penyampaian materi. Pada materi teknologi pengolahan ikan, materi meliputi teknik pengoalahan ikan atau proses pengolahan ikan yang dapat dilakukan dengan beberapa cara mulai dari cara tradisional dan dengan cara moderen yang meliputi penggaraman, penjemuran, pengasapan, pemindangan, permentasi, pendinginan dengan es, dan pendinginan dengan mesin pendingin. Pelatihan pengawetan ikan menggunakan mesin pendingin meliputi pengenalan mesin pendingin, proses pendinginan ikan dengan mesin, capaian suhu pendinginan, perawatan mesin pendingin. Setelah presentasi materi kemudian dialkukan tanya jawab dengan masyarakat kelompok nelayan. Kemudian dilakukan evaluasi untuk mengetahui tingkat pemahaman penguasaan materi yang telah dijelaskan.

Selama pelaksanaan pelatihan respon dari masyarakat sangat merespon positif, selalu mengikuti pelatihan dan penyuluhan dengan semangat dan sangat terasa bermanfaaat karena awalnya mereka kurang mengerti atau kurang paham menjadi meningkat pemahamannya dan mereka selalu menginginkan dan berharap adanya dampingan teknis kedepannya terkait penggunaan mesin pendingin dan perawatannya, dan tidak hanya sisi teknis saja tetapi dari sisi manajemen juga. Oleh karena itu tim pengabdi siap melakukan pendampingan bilamana dibutuhkan oleh masyarakat nelayan mengenai penanganan mesin pendingin secara teknis maupun manajemen. Berikut ini ditampilkan beberapa foto kegiatan dalam pelaksanaan pengabdian. 


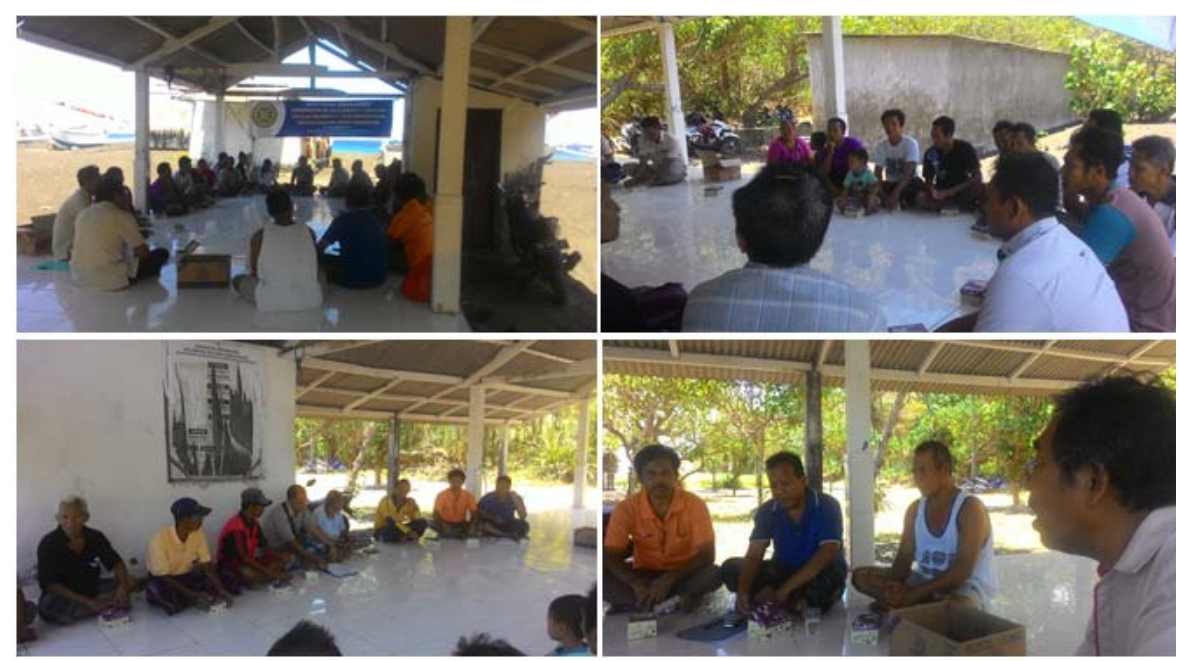

Gambar 1. Pelaksanaan Kegiatan Pengabdian

\section{KESIMPULAN DAN SARAN}

Pelaksanaan pengabdian dapat berjalan dengan lancar sesuai rencana kerja yang dijadwalkan. Selama pelaksanaan pelatihan respon dari masyarakat sangat positif, selalu mengikuti pelatihan dan penyuluhan dengan semangat dan sangat terasa bermanfaaat karena awalnya mereka kurang mengerti atau kurang paham menjadi meningkat pemahamannya dan mereka selalu mengiginkan atau berharap adanya dampingan teknis kedepannya terkait penggunaan mesin pendingin dan perawatannya, dan tidak hanya sisi teknis saja tetapi dari sisi manajemen juga.

Selain topik yang telah disampaikan tentang pengolahan ikan, yang perlu ditingkat pada kelompok nelayan adalah peningkatan pemahaman manajemen pengelolaan keuangan, usaha-usaha lain yang berkaitan, dan juga manajemen pemasaran.

\section{UCAPAN TERIMAKASIH}

Ucapan terimakasih kepada DIPA PNPB Universitas Udayana yang telah mendanai pengabdian, LPPM Universitas Udayana yang telah memediasi kegiatan ini, kelompok nelayan Amerta Segara yang telah bermitra dan semua pihak yang mendukung pelaksanaan pengabdian.

\section{DAFTAR PUSTAKA}

Adawyah (2007). Pengolahan dan Pengawetan Ikan. Jakarta, Bumi Aksara.

Isamu Kobajashi T., Hari Purnomo Dan Sudarminto S. Yuwono (2012) 'Karakteristik Fisik, Kimia, Dan Organoleptik Ikan Cakalang (Katsuwonus Pelamis) Asap Di Kendari', Jurnal Teknologi Pertanian, Agustus 2012, 13(2), pp.105-110.

Junianto (2003) 'Teknik Pengolahan Ikan', Penerbit Swadaya.

DKP Bali (2008) 'Potensi Perikanan Bali (https://dkpbali.wordpress.com/2008/10/29// (Diunduh 2 Februari 2017).

DKP Bali (2014) 'Potensi dan Persebaran Sumber Daya Laut', http://ipsgampang. blogspot.co.id/2014/08/ 14.html/ (Diunduh 2 Februari 2017).

Sanger, Grace (2010) 'Oksidasi Lemak Ikan Tongkol (Auxfs Thazardl Asap Yang Direndam Dalam Larutan Ekstrak Daun Sirih', Pacific Journal Juli 2010, 2 (5), pp. 870 -873.

Swastawati, Fronthea (2011) 'Studi Kelayakan Dan Efisiensi Usaha Pengasapan Ikan Dengan Asap Cair Limbah Pertanian', Fakultas Perikanan Dan Ilmu Kelautan Universitas Diponegoro. Semarang. 
Pemberdayaan Masyarakat Nelayan melalui Pelatihan Pengawetan Ikan Menggunakan Mesin Pendingin

Wibowo S, (1996) 'Industri Pengolahan Ikan’, Penebar Swadaya. Jakarta.

W.F. Stoecker (1980) 'Refrigeration and Air Conditionning', McGraw-Hill, New Delhi. 